To appear in: Archaeology International (2006)

\title{
The Sociocultural Theatre and the Evolutionary Play
}

\author{
by James Steele
}

AHRC Centre for the Evolution of Cultural Diversity, Institute of Archaeology, University

College London, 31-34 Gordon Square, London WC1H OPY, UK. Email: j.steele@ucl.ac.uk

The Arts and Humanities Research Council is once again investing in evolutionary archaeology. The investment is not a trivial one. In 2001, the Council funded a Research Centre - based at UCL, and with an out-station at Southampton - to work for five years on the evolutionary analysis of cultural behaviour. It was one of only eleven such national Research Centres funded in this way, and the only one to be led by archaeologists. Such was the success of this Centre that the AHRC has now decided to fund it for another five years of work. Only one other AHRC Research Centre has received such renewed investment. The re-named AHRC Centre for the Evolution of Cultural Diversity was inaugurated in January 2006, with a programme of activities that will keep its researchers extremely busy until Christmas 2010. It remains based at UCL, with its offices in the Institute of Archaeology, and I have taken up the post of Centre Director.

\section{Evolutionary culture theory}

The Centre's new award confirms that evolutionary culture theory is now firmly established in the research landscape of the arts and humanities. For many, however, the basis of the approach is still a mystery. We have set ourselves the challenge of clearing up any confusion, by allocating substantial effort to communication and outreach.

Our field encompasses genetics as a window on human population history, but also involves the comparative study of human languages, social systems, and material culture. Unifying these is a Darwinian approach to human agency and cultural diversity. Such an approach focuses on the relationship between the evolution of gene frequencies and the evolution of distributions of cultural traits. The principle is very simple. Given some reasonable assumptions about human cognitive and social psychology (how we make choices and how we learn from others), and given some other (but also reasonable) assumptions about the stability of cultural representations as they are transferred between individuals, we can then apply quantitative models of the evolution of cultural traditions that bear some similarity to the models used to make sense of biological diversity.

Beneath this umbrella, at least three main positions exist ${ }^{1}$. For human behavioural ecologists, the relationship between genes and culture is tightly bound by the expectation that human cultural systems and social agency serve to maximize individuals' reproductive fitness. Others are less convinced. Dual inheritance theorists recognize that humans adopt efficient rules-of-thumb for social learning, especially regarding whom to imitate when one is uncertain about the relative advantages of any one among a number 
of alternatives. These rules-of-thumb usually work - that is, they provide us with a low risk, time-efficient route to an optimal set of beliefs, attitudes and skills in an uncertain world. But things can go wrong: given such biases and propensities to adopt behaviour copied from others without a proper and full evaluation, ideas can spread even when they might prove to be harmful. Finally, evolutionary psychologists are less sanguine still. They recognize that the human mind has evolved cognitive mechanisms to meet practical challenges and solve real world problems, but that these mechanisms arose in very different contexts to those of the modern world. Such hard-wired rules-of-thumb, however well they worked in the past, may sometimes now show up as limiting factors or unwelcome biases: culture is evolving too fast, and our mental hardware cannot always keep up.

These three positions - human behavioural ecology, dual inheritance theory, and evolutionary psychology - are not fully reconcilable. Nonetheless, they have proved a fertile source of ideas and hypotheses for scholars in a wide range of disciplines, each of whom is committed to a scientific understanding of human cultural diversity. These scholars share an expectation both that human agency is governed by cognitive biases and decision rules that tend to increase reproductive fitness, certainly in our evolutionary past and possibly also even today; and that large scale patterns of cultural diversity are the aggregated outcome of individuals expressing such biases and decision rules in their day-to-day activities. Group-level processes are of course also important, not least for understanding the emergence of stable social institutions for collective action; their explanation in terms of individual-level processes is a focus of much current work ${ }^{2}$, as is the evolutionary psychology of religion, seen as a norm-enforcing social mechanism ${ }^{3}$.

Much of the first generation of work on this approach took place in the United States. Key studies in the 1980s by Cavalli-Sforza and Feldman ${ }^{4}$, and by Boyd and Richerson ${ }^{5}$, laid the groundwork for a mathematical model of cultural transmission and its dynamics. Evolutionary approaches in psychology have also been prominent in the USA, thanks partly to the 'Santa Barbara' school'; but a more moderate approach has also been prominent since the 1980s, and is seen in an influential body of work on social intelligence and on 'theory of mind" ${ }^{7}$. A number of new initiatives have also emerged in Europe to promote an integrated evolutionary approach in the social sciences, including the Max Planck Institute for Evolutionary Anthropology in Germany (founded in 1997), and the Leverhulme Centre for Human Evolutionary Studies in Cambridge (founded in 2000). The McDonald Institute for Archaeological Research in Cambridge has also been a forerunner in this field. Our own AHRC Centre, with the benefit of Stephen Shennan's able leadership in its first phase, has now become an established player and has been the source of many innovative applications of evolutionary approaches in the field of material culture studies.

\section{New approaches to cultural diversity}

What then, in practice, does an evolutionary approach to culture involve? One focus of our work has been on rates of innovation - which is the source of cultural variation, 
analogous to mutation and/or recombination in genetics. Bentley and co-workers have studied distributions of traits in systems which are highly internally diverse and have high turnover rates - modern baby names, contemporary chart pop music, prehistoric pottery design motifs - to identify dynamics which are consistent with a neutral model ${ }^{8}$. This model, derived from genetics, assumes that neutral mutations occur at a constant rate, and that the rates at which individual traits are propagated (in cultural systems, through imitation) randomly vary. A consequence of this is that the frequency distribution of variants can be described by a 'power law' curve, whose coefficient (a measure of the concentration of abundance in a small number of variants) scales with the population size and the rate of innovation. Lake and Venti, meanwhile, have studied the evolution of diversity in new technologies where variation is not neutral, using the well-documented case of the history of bicycles ${ }^{9}$. The pattern is one of initially high diversity, subsequently winnowed to leave a small number of successful design solutions each with its own historical design lineage. Lake and Venti see this as the collective outcome of individuals initially searching widely across a 'technology landscape', analogous to the high initial diversity of biological forms seen in adaptive radiations like the Cambrian event.

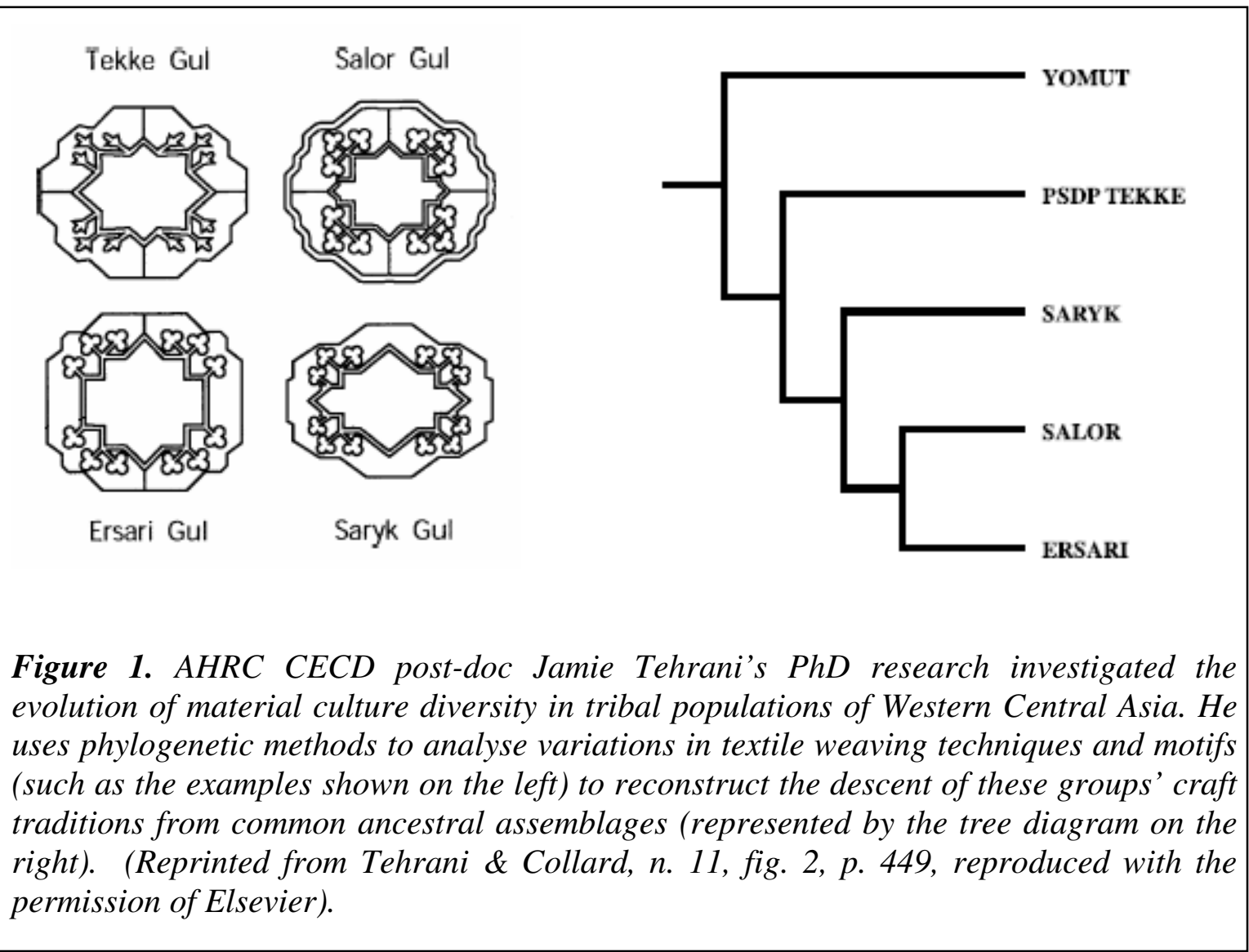

A second focus of our work has been on the social interactions which provide the pathways for cultural transmission. One source of conservatism, or historical continuity in cultural patterns, is vertical transmission - the transfer of knowledge between generations, often from parents to offspring. Some time ago Shennan and I found that craft skills in societies with a household mode of production tend to be transmitted in this 
way, and usually between parent and offspring of the same sex ${ }^{10}$. At a larger scale, Collard, Tehrani, Jordan and co-workers have been investigating vertical transmission and cultural diversity in the ethnographic record (see Figure 1$)^{11}$. This investigation is facilitated when language differences between societies now in close geographical proximity reflect a migration event by one group in the relatively recent past. They find that some cultural similarities reflect recent interactions among neighbours, but others must reflect more deep-rooted and conservative historical traditions - with the two patterns having different degrees of importance in different aspects of craft design and technique.

The counterpart to such vertical transfers of knowledge is horizontal transmission sometimes taken to mean transfers among unrelated individuals of the same generation, but also including the larger-scale geographical diffusion of ideas and practices. Work by Colledge, Conolly, and co-workers has focused on the transition to agriculture in Europe, tracking the spread of different strains of domesticated cultivars ${ }^{12}$. Work by Gkiasta, Russell and co-workers had previously mapped the large-scale chronology of the transition, and had addressed the problem of differentially diagnosing two local growth and dispersal processes - demic diffusion (dispersal of people) and cultural adoption (dispersal of ideas) - from the archaeology ${ }^{13}$.
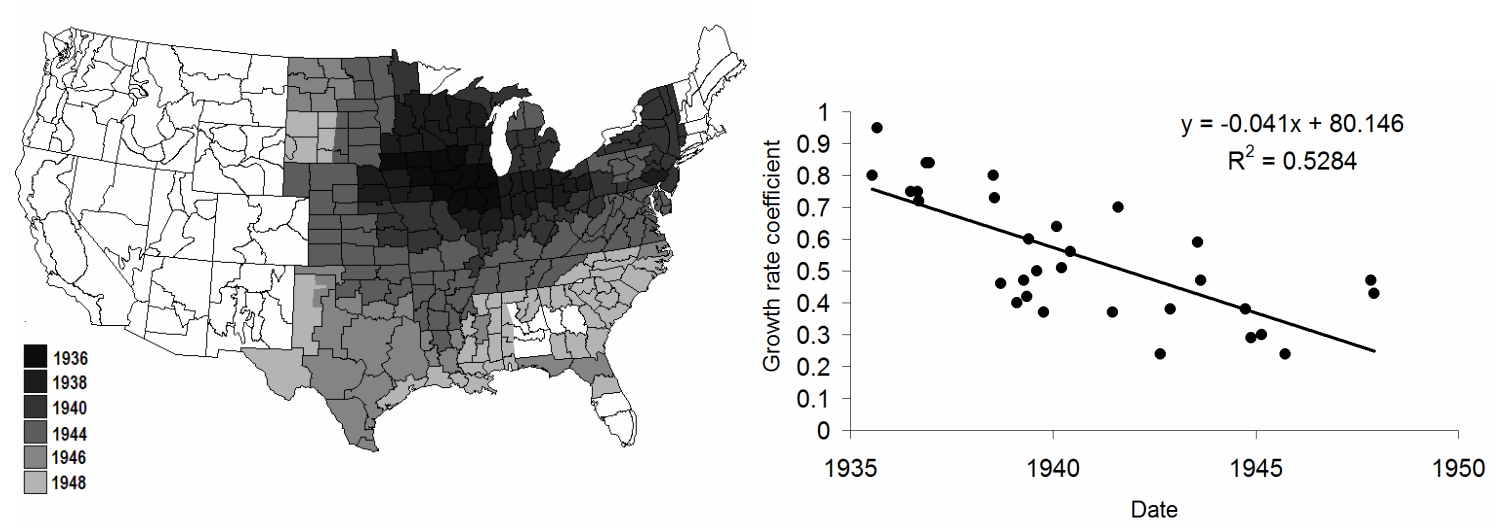

Figure 2. (a) Diffusion of hybrid corn usage, showing areas that planted 10 or more percent of their corn acreage to hybrid seed at successive time intervals (redrawn after Griliches 1960). (b) Within-state rate of increase of hybrid corn use, plotted against the date of arrival in each state (the date at which hybrid corn reached $10 \%$ of all corn). Data from Griliches (1957) with revised growth coefficient estimates from Dixon (1980; coefficient $b_{2}$ ). From Steele (forthcoming).

Modern case studies help to explain the dynamics of cultural change, and the situations may have similarities to those seen in the archaeological record. In the middle of the $20^{\text {th }}$ century a higher-yielding hybrid strain of corn was developed and gradually adopted in the United States. The pattern of spatial diffusion (Figure 2a) implies a dual inheritance explanation for farmer's adoption decisions - i.e., a contagion-like spread influenced by proximity and by imitation of prior adopters. However, the scatterplot (Figure 2b) suggests a rational choice explanation. Later-adopting states - which tend also to be those 
where agricultural productivity is lower, and where farm sizes are smaller - substituted the new strain for the older strains at a slower rate. Probable reasons for this are that suppliers of the new strain preferentially targeted the Corn Belt states first; that the potential for increased yield was less apparent to farmers in the less productive regions; and that there was regional variation in the allocation of effort on selective breeding of hybrids adapted to local conditions by agricultural experimental stations in different states. In this modern case, the process was very fast - instantaneous on an archaeological time scale - and there is no likelihood that demic diffusion explains the spatial pattern. This process was therefore not comparable to the Neolithic transition in Europe. In both cases, however, local variation in crop growing conditions would have been an important factor influencing rates of spread.

A third focus of our work is on developing rigorous comparative methods to identify cultural adaptations. We cannot simply record the frequency with which a particular cultural trait is associated with a particular feature of economy or environment, and then - if the associations occur often - assume that this is because the cultural trait is adaptive. This is because societies may occupy similar environments and have similar practices simply because they are closely historically related. We want to be able to study many independent instances where historically closely-related societies vary in their ecological and socio-economic characteristics. If, in all or most such instances, the society which has adopted a new economic strategy ' $\mathrm{X}$ ' or responded to a new ecological challenge ' $\mathrm{Y}$ ' has done so by innovating a new cultural solution ' $\mathrm{Z}$ ', then we can be confident that this is because such societies are converging on a single optimal solution - that is, we are seeing cultural adaptation. Holden and Mace have developed and applied this comparative method, confirming - in Bantoid language-speaking pastoralists of subSaharan Africa - the adaptive significance of the association found between cattlekeeping, and a switch from matriliny to a patrilineal or mixed pattern of descent and group membership ${ }^{14}$. As part of this project, Holden has also generated a new language tree showing the probable historical relationships among the languages in the Bantu family ${ }^{15}$.

\section{New directions for the second Phase}

During the second Phase of the Centre, work will continue in these areas, divided among three major themes. We will develop a new focus cutting across all three of these themes on questions relevant to the Palaeolithic period, specifically, the evolution of spoken language and its relationship to the evolution of tool-making and tool-using skills ${ }^{16}$.

Theme A: Demographic processes and cultural change. We shall examine the relationship between demographic factors (population size, structure, and stability), and cultural diversity. The relation of population dispersals arising from subsistence innovations to language family expansions has been widely discussed in recent years, and models have also been proposed for the cultural significance of population decline. It is often suggested that, at least before the origin of states, the emergence of new adaptations supporting higher population densities and population expansions was the main basis for cultural macro-evolution. We shall examine such hypotheses and develop an analytical 
framework with which to test them, involving co-operation between archaeologists, anthropologists, geneticists and behavioural biologists.

Theme B: Cultural and linguistic diversity. We shall examine the relationship of evolutionary change in linguistic systems to that in social practices and in material cultural traditions. Understanding the relationship between linguistic and cultural descent, the extent to which they are branching or reticulating, and the factors affecting their descent histories is central to explaining how cultural diversity arises and how it is maintained. Have cultures always mixed and hybridised as they have come into contact with one another, or have groups maintained boundaries that insulate them strongly from outside influence, so that difference arises largely when groups split and move apart? We shall continue to explore such issues, with archaeologists and anthropologists working in close collaboration with historical linguists.

Theme C: Innovations in complex social networks. We shall examine the extent to which the growing scale and complexity of human social networks has changed the speed and/or the manner in which new cultural variation is generated. We will examine spatial and network aspects of the diffusion of innovations at a general level, and we shall examine the effects of interaction patterns on innovation rates in pre-industrial urban societies. This theme will enable the Centre to involve archaeologists and anthropologists working on early state-level societies.

The Phase 2 Centre will therefore be more interdisciplinary, involving geneticists, linguists, and behavioural biologists, as well as archaeologists and anthropologists. It will also engage more actively with non-specialists and skeptics, to promote its work but also to identify the existing limits of the various approaches. These activities are only now getting under way, and we will report on them, and on the Centre's continuing progress, in future issues of Archaeology International.

\footnotetext{
${ }^{1}$ Smith, E.A. (2000) Three styles in the evolutionary study of human behavior. In L. Cronk, N. Chagnon and W. Irons (eds) Adaptation and Human Behavior: an Anthropological Perspective, pp. 27-46. Hawthorne, NY: Aldine de Gruyter.

${ }^{2}$ McElreath, R., Boyd, R., \& Richerson, PJ (2003). Shared norms and the evolution of ethnic markers. Current Anthropology 44: 122-129.

${ }^{3}$ Johnson, D. (2005) God's punishment and public goods: A test of the Supernatural Punishment Hypothesis in 186 world cultures. Human Nature 16: 410-446.

${ }^{4}$ Cavalli-Sforza, LL and Feldman, MW (1981) Cultural Transmission and Evolution: A Quantitative Approach. Princeton University Press, Princeton, USA.

${ }^{5}$ Boyd, R. \& Richerson, PJ (1985). Culture and the Evolutionary Process. Chicago, Illinois: University of Chicago Press.

${ }^{6}$ Barkow, J., Cosmides, L. \& Tooby, J. (Eds.), The adapted mind: Evolutionary psychology and the generation of culture. New York: Oxford University Press.

${ }^{7}$ Povinelli, DJ and Preuss, TM (1995) Theory of mind: evolutionary history of a cognitive specialization. Trends in Neurosciences 18: 418-424.

${ }^{8}$ Bentley, R. A., M.W. Hahn and S. J. Shennan (2004). Random drift and culture change. Proceedings of the Royal Society Biology (DOI:10.1098/rspb.2004.2746).

${ }^{9}$ Lake, M \& Venti, J. (forthcoming) A quantitative analysis of macroevolutionary patterning in technological evolution: bicycle design from 1800 to 2000. In S. Shennan (ed.) Pattern and Process in Cultural Evolution.
} 
${ }^{10}$ Shennan, S J \& Steele, J, 1999. Cultural learning in hominids: a behavioural ecological approach, in H Box and K Gibson (eds), Mammalian Social Learning: Comparative and Ecological Perspectives, 367388. (Symposia of the Zoological Society of London 72). Cambridge University Press

${ }^{11}$ Tehrani, J. and M. Collard (2002) Investigating cultural evolution through biological phylogenetic analyses of Turkmen textiles. Journal of Anthropological Archaeology 21:443-463.; Jordan, P. and S.J. Shennan (2003) Cultural transmission, language and and basketry traditions amongst the California Indians. Journal of Anthropological Archaeology 22:42-74.

${ }^{12}$ Colledge, S., J. Conolly and S. Shennan, 2004. Archaeobotanical evidence for the spread of farming in the East Mediterranean. Current Anthropology 45.S4, S35-S58.

${ }^{13}$ Gkiasta, M., T. Russell, S.J. Shennan and J. Steele 2003. Origins of European agriculture: the radiocarbon record revisited. Antiquity 77: 45-62

${ }^{14}$ Holden, C., and R. Mace. (2003) Spread of cattle led to the loss of matriliny in Africa. A co-evolutionary analysis. Proceedings of the Royal Society B 270: 2425-2433.

${ }^{15}$ Holden,C. (2002) Bantu language trees reflect the spread of farming across sub-Saharan Africa: a maximum-parsimony analysis. Proceedings of the Royal Society of London B 269: 793-799.

${ }^{16}$ Buckley, C. and J Steele (2002). Evolutionary ecology of spoken language: co-evolutionary hypotheses are testable. World Archaeology 34: 26-46.; Steele, J. \& Uomini, N. (2006) Humans, tools and handedness. In V Roux et al, eds. Knapping Stone, pp. 217-239. Cambridge: MacDonald Institute.

\section{Additional references:}

Dixon, R. (1980) Hybrid corn revisited. Econometrica 48: 1451-1461.

Griliches, Z. (1957) Hybrid corn: an exploration in the economics of technological change. Econometrica 25: 501-522.

Griliches, Z. (1960) Hybrid corn and the economics of innovation. Science 132: 275-280.

Steele, J. (forthcoming) Innovation diffusion and travelling waves. In S. Shennan, ed., Pattern and Process in Cultural Evolution. 